\title{
Comprehensive HIV/AIDS knowledge and safer sex negotiation among adolescent girls and young women in sub-Saharan Africa
}

\author{
James Boadu Frimpong ${ }^{1 *}(\mathbb{D})$, Eugene Budu ${ }^{2}$, Collins $\mathrm{Adu}^{3}\left(\mathbb{D}\right.$, Aliu Mohammed ${ }^{1}$ (D), \\ Justice Kanor Tetteh ${ }^{2}$ (D), Abdul-Aziz Seidu ${ }^{2,4,5}$ (D) and Bright Opoku Ahinkorah ${ }^{6}$
}

\begin{abstract}
${ }^{1}$ Department of Health, Physical Education and Recreation, University of Cape Coast, Cape Coast, Ghana, ${ }^{2}$ Department of Population and Health, University of Cape Coast, Cape Coast, Ghana, ${ }^{3}$ Department of Health Promotion, Education and Disability Studies, Kwame Nkrumah University of Science and Technology, Kumasi, Ghana, ${ }^{4}$ College of Public Health, Medical and Veterinary Sciences, James Cook University, Australia, ${ }^{5}$ Department of Estate Management, Takoradi Technical University, Takoradi, Ghana and ${ }^{6}$ School of Public Health, Faculty of Health, University of Technology Sydney, Sydney, Australia

*Corresponding author. Email: frimpongboadujames@gmail.com
\end{abstract}

(Received 25 February 2021; revised 26 July 2021; accepted 27 July 2021; first published online 24 September 2021)

\begin{abstract}
Globally, HIV/AIDS remains a public health issue, especially in sub-Saharan Africa (SSA). Despite the increased advocacy and dissemination of comprehensive HIV/AIDS information in SSA, it appears that little progress has been made to reduce the incidence of HIV/AIDS in the sub-region. This study, therefore, examined the association between comprehensive HIV/AIDS knowledge and safer sex negotiation among adolescent girls and young women in SSA. Data were taken from the Demographic and Health Surveys conducted between 2010 and 2019 in 30 countries in SSA. The study sample comprised 37,364 adolescent girls and young women aged 15-24. A multivariable binary logistic regression analysis was done to test the hypothesis that there is a positive association between comprehensive HIV/AIDS knowledge and safer sex negotiation. Adolescent girls and young women who had comprehensive knowledge on HIV/AIDS were more likely to negotiate for safer sex compared with those who had no comprehensive knowledge on HIV/AIDS (AOR=1.31, 95\% CI: 1.22-1.41). At the country level, the positive association between comprehensive knowledge on HIV/AIDS and safer sex negotiation was significant in Chad, Congo DR, Gambia, Guinea, Liberia, Ethiopia and Malawi. On the other hand, in Togo, adolescent girls and young women who had comprehensive HIV/AIDS knowledge were less likely to negotiate for safer sex. These findings can inform policies and programmes on the crucial role of comprehensive HIV/AIDS education and knowledge in increasing safer sex negotiation among adolescent girls and young women in SSA. The study recommends that Togo needs to address certain practices such as intimate partner violence against adolescent girls and young women, which prevent them from negotiating for safer sex, despite their higher knowledge on comprehensive HIV/AIDS. Lessons can be learnt from Chad, Congo DR, Gambia, Guinea, Liberia, Ethiopia and Malawi about the scale-up of programmes and interventions targeted at young women.
\end{abstract}

Keywords: Comprehensive HIV/AIDS knowledge; Safer sex negotiation; Adolescent girls and young women

\section{Introduction}

HIV/AIDS remains a public health concern in sub-Saharan Africa (SSA) (World Health Organization [WHO], 2018). Global statistics reveal that approximately 37 million people were infected with HIV in 2017, of which nearly 2 million were newly infected cases (WHO, 2018). To 
further reduce the cases of HIV each year, efforts to improve comprehensive knowledge on HIV in various populations, especially the young and sexually active population, have been intensified, yet with little success (Badru et al., 2020). Adolescent girls and young women (AGYW) in SSA are at higher risk of contracting HIV than their male peers as a result of early marriage, which predisposes them to HIV acquisition (Mavhu et al., 2018). Hence, there is a need to focus health education and HIV prevention strategies on this vulnerable group (UNAIDS, 2016; Saul et al., 2018).

Unprotected sex is among several factors that account for new HIV infections among AGYW (Wang et al., 2012; Sathiyasusuman, 2015; Mwale \& Muula, 2018). Also, lack of comprehensive knowledge on HIV has been identified as one of the critical factors contributing to the surge in the incidence of new cases of HIV among AGYW (Siziya et al., 2008; Darteh, 2020). Other factors, including mass media exposure and having attained a secondary or higher level of education, have been found to be predictors of comprehensive HIV knowledge among AGYW (Darteh, 2020). Comprehensive HIV knowledge is low among AGYW in Ghana, and is predicted by marital status, education, region and exposure to mass media (Darteh, 2020). However, a study in Malawi found a high level of comprehensive HIV knowledge among AGYW, depending on age, level of education, wealth index, mass media exposure and employment status (Mandiwa et al., 2021).

In SSA, AGYW's ability to negotiate for safer sex has been a major problem associated with HIV incidence since men are regarded as being more influential and domineering when it comes to sexuality decision-making (Saul et al., 2018; Darteh, 2020). In light of this, the Sustainable Development Goal (SDG) 5 focuses on gender equality to enhance AGYW's control in reproductive issues, attitudes and their overall ability to negotiate for safer sex with their male partners (Exavery et al., 2012; Darteh et al., 2019). In SSA, interventions such as comprehensive sex education, the promotion of condom use, Determined, Resilience, Empowered, AIDS-free, Mentored and Safe (DREAMS), among others, aim to enhance AGYW's control in reproductive issues and these efforts are making some progress (Saul et al., 2018). Several socioeconomic and cultural factors, including place of residence, marital status, age and educational level, have been found to be associated with AGYW's ability to negotiate for safer sex (Exavery et al., 2012; Darteh et al., 2014; Ameyaw et al., 2017).

Evidence suggests that HIV knowledge enhances an individual's ability to negotiate for safer sex, which in turn is linked to a reduction in HIV incidence (De Coninck et al., 2014). For instance, an AGYW who has knowledge about HIV and asks a partner who has contracted or been exposed to HIV to use a condom may be less likely to become infected with the virus. Despite the established link between comprehensive HIV knowledge and safer sex negotiation, and how this contributes to a reduction in HIV incidence, little research attention has been given to this phenomenon in SSA. To the best of the authors' knowledge, there is limited evidence regarding the association between comprehensive HIV/AIDS knowledge and safer sex negotiation among AGYW in SSA. Therefore, this study aimed to examine the association between comprehensive HIV/AIDS knowledge and safer sex negotiation among AGYW in SSA using data from the Demographic and Health Surveys (DHSs). The findings of the study could help inform policy formulation in the sub-region in order to reduce the incidence of HIV/AIDS and unintended pregnancies.

\section{Methods}

\section{Data and study sample}

The study used data from the DHSs conducted between 2010 and 2019 across 30 countries in SSA. Specifically, data from the women's recode files were used. The DHS is a nationally representative household survey that is conducted in more than 85 low- and middle-income countries worldwide. It focuses on essential indicators including comprehensive HIV/AIDS knowledge and safer sex negotiation (Corsi et al., 2012). Respondents for the DHS are selected using a two-stage sampling approach stratified by rural and urban locations, which ensures that the data are nationally representative (Corsi et al., 2012). For details of the DHS sampling process, 
Table 1. Countries, survey years and study sample of adolescent girls and young women in sub-Saharan Africa

\begin{tabular}{|c|c|c|c|}
\hline Country & Year of survey & Weighted $n$ & Weighted \% \\
\hline Burkina Faso & 2010 & 2845 & 4.61 \\
\hline Benin & $2018-19$ & 776 & 2.08 \\
\hline Burundi & $2016-17$ & 1546 & 4.14 \\
\hline Congo DR & 2013-14 & 1765 & 4.72 \\
\hline Congo & 2011-12 & 1024 & 2.74 \\
\hline Cote D'Ivoire & 2011-12 & 676 & 1.81 \\
\hline Cameroon & 2018 & 1386 & 3.71 \\
\hline Ethiopia & 2016 & 1357 & 3.63 \\
\hline Gabon & 2012 & 634 & 1.70 \\
\hline Ghana & 2014 & 488 & 1.31 \\
\hline Gambia & 2013 & 1131 & 3.03 \\
\hline Guinea & 2018 & 682 & 1.83 \\
\hline Kenya & 2014 & 1483 & 3.97 \\
\hline Comoros & 2012 & 306 & 0.82 \\
\hline Liberia & 2013 & 803 & 2.15 \\
\hline Lesotho & 2014 & 236 & 0.63 \\
\hline Mali & 2018 & 1269 & 3.40 \\
\hline Malawi & $2015-16$ & 4143 & 11.09 \\
\hline Mozambique & 2015 & 822 & 2.20 \\
\hline Nigeria & 2018 & 2560 & 6.85 \\
\hline Niger & 2012 & 1142 & 3.05 \\
\hline Namibia & 2013 & 351 & 0.94 \\
\hline Rwanda & $2014-15$ & 870 & 2.33 \\
\hline Sierra Leone & 2019 & 1137 & 3.04 \\
\hline Senegal & $2010-11$ & 1528 & 4.09 \\
\hline Chad & 2014-15 & 309 & 0.83 \\
\hline Togo & 2013-14 & 655 & 1.75 \\
\hline Uganda & 2016 & 2738 & 7.33 \\
\hline Zambia & 2018-19 & 1488 & 3.98 \\
\hline Zimbabwe & 2015 & 1216 & 3.25 \\
\hline All countries & & 37,364 & 100.00 \\
\hline
\end{tabular}

see Seidu et al. (2020). A total of 37,364 AGYW (15-24 years) who had complete information on all the variables of interest were included in this study. The Strengthening the Reporting of Observational Studies in Epidemiology (STROBE) statement informed the study design (Von Elm et al., 2007). Table 1 gives a detailed description of the countries, survey years and study sample. The datasets for the DHS can be accessed freely at https://dhsprogram.com/data/ available-datasets.cfm 


\section{Outcome variable}

The outcome variable was 'safer sex negotiation'. This was derived as a composite variable from two questions, 'Can you ever refuse sex with your partner?', and 'Can you ever ask your partner to use a condom during sex?' Responses to these questions were 'yes' or 'no'. For the purposes of this study, respondents who answered 'yes' to at least one of the two questions were considered to be able to negotiate for safer sex and were assign the code 'yes' and otherwise as 'no'.

\section{Main explanatory variable}

The main explanatory variable was 'comprehensive knowledge on HIV/AIDS'. This is defined as correctly knowing two ways to prevent HIV transmission and rejection of the three most common misconceptions about HIV (Ochako et al., 2011). This variable was measured by asking each woman whether or not she agreed with the following five statements: (a) Consistent use of condoms during sexual intercourse can prevent HIV transmission; (b) Limiting sex to just one uninfected faithful partner can prevent HIV transmission; (c) A healthy-looking person can have HIV; (d) A person can get HIV through mosquito bites; (e) A person can get HIV by sharing food with an HIV-infected person (Ochako et al., 2011; Agegnehu et al., 2020; Darteh, 2020). A composite score based on the correct answers to the preceding questions was used to derive a 'comprehensive knowledge on HIV/AIDS' score, which was dichotomously coded as 'Yes' = 1 (correctly responding to all five questions) and 'No' $=0$ (incorrectly responding to at least one of the questions).

\section{Control variables}

Eleven control variables were considered, broadly clustered into individual level and contextual variables. Individual level variables included age, occupational status, marital status, educational level, frequency of reading newspapers, frequency of listening to the radio, frequency of watching the television, condom use and number of current sexual partners. Contextual variables were wealth index and type of place of residence. These variables were not determined a priori; but were instead based on parsimony, theoretical relevance and practical significance with safer sex negotiation (Bharat et al., 2013; Atteraya et al., 2014; Sunmola et al., 2018).

\section{Statistical analyses}

Data analyses were conducted using Stata version 14.0 (Stata Corporation, College Station, TX, USA). The first step was the determination of the prevalence of safer sex negotiation and comprehensive knowledge on HIV/AIDS among the respondents in each of the 30 sub-Saharan African countries surveyed. Next, the relationship between the explanatory and control variables and the outcome variable (safer sex negotiation) was analysed using Pearson's chi-squared test. This was followed by the use of a multivariable binary logistic regression to examine the association between comprehensive knowledge and HIV/AIDS and safer sex negotiation among the respondents. Finally, the association between comprehensive knowledge on HIV/AIDS and safer sex negotiation in each of the 30 countries was assessed using logistic regression models. The results of the regression analysis are presented as crude odds ratios (CORs) and adjusted odds ratios (AORs) at $95 \%$ confidence intervals (CIs).

The women's sample weight (v005/1,000,000) was applied to correct for over- and undersampling and the survey command (svy) in Stata was used in both the chi-squared and regression analyses to account for the complex survey design and generalizability of the findings. According to Hatt and Waters (2006), pooling data can bring about broader results that are 'often obscured by the noise of individual data sets'. To calculate the pooled values, further adjustment was needed to account for the variability in the number of individuals sampled in each country. This was accomplished using the weighting factor $1 /\left(A^{\star} n_{c} / n_{t}\right)$, where $A$ is the number of countries that 


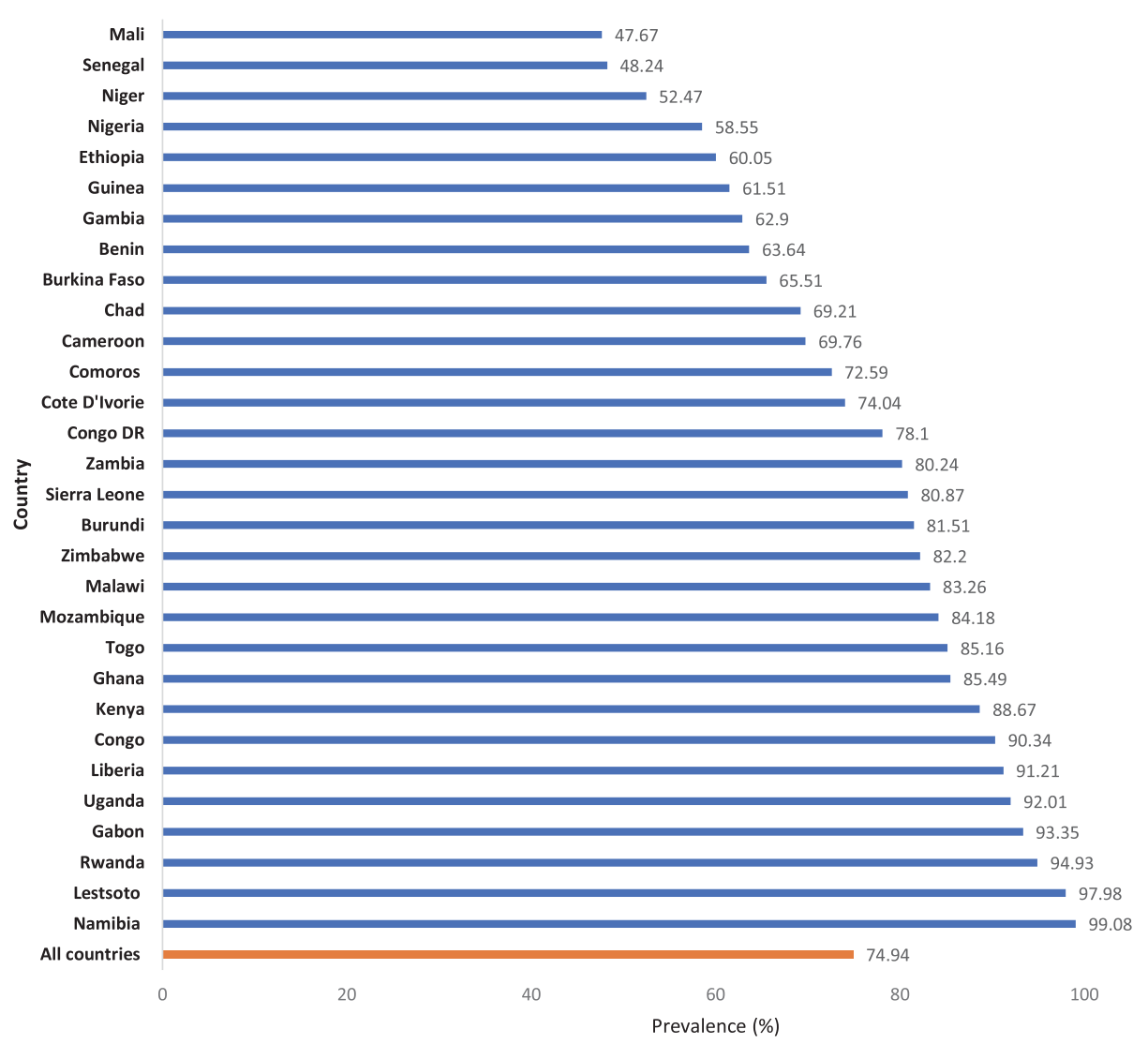

Figure 1. Prevalence of safer sex negotiation among AGYW in 30 countries in SSA.

asked a particular question, $n_{c}$ is the number of respondents in a country $c$ and $n_{t}$ is the total number of respondents over all countries asked the question (Peng et al., 1998).

\section{Results}

\section{Prevalence of comprehensive HIV/AIDS knowledge and safer sex negotiation}

The overall prevalence of safer sex negotiation among AGYW in the 30 sub-Saharan African countries was $74.9 \%$, ranging from $47.7 \%$ in Mali to $99.1 \%$ in Namibia (Figure 1). The overall prevalence of comprehensive HIV/AIDS knowledge in the 30 countries in SSA was $41.6 \%$, with the highest in Rwanda (74.3\%) and lowest in Congo (15.0\%) (Figure 2).

\section{Distribution of safer sex negotiation by knowledge on HIV/AIDS and other covariates}

Table 2 presents the results of the bivariate analysis of comprehensive HIV/AIDS knowledge, control variables and safer sex negotiation among AGYW in SSA. A larger proportion (80.1\%) of respondents with comprehensive knowledge on HIV/AIDS had safer sex negotiation than those with no comprehensive knowledge on HIV/AIDS (71.3\%). More than three-quarters of women aged 20-24 (76.5\%) had higher safer sex negotiation than those aged 15-19 (70.3\%). A higher proportion of women who were working $(77.2 \%)$ had safer sex negotiation than those who were not working (71.0\%). Those who were cohabiting (88.4\%), who had secondary or higher education 


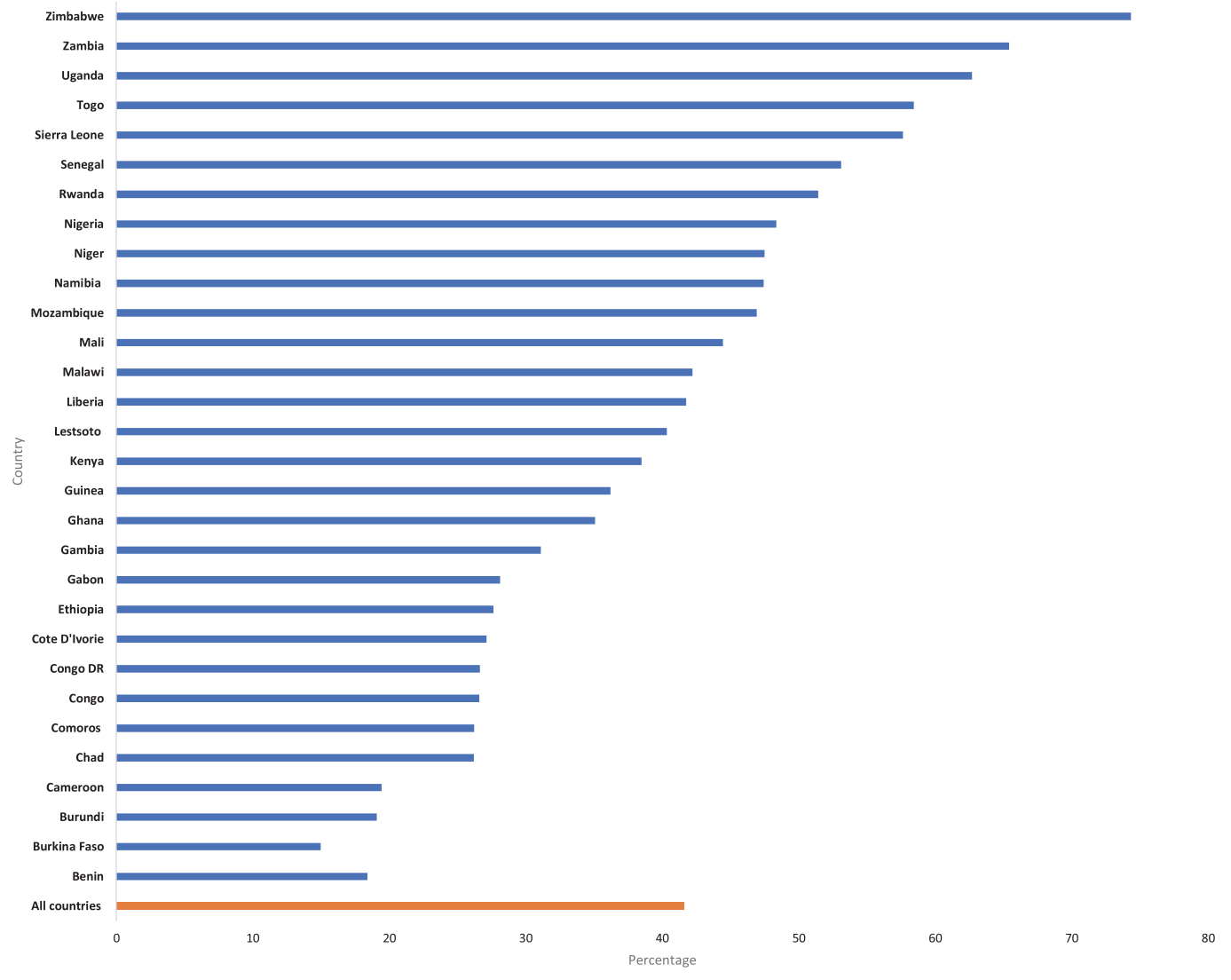

Figure 2. Prevalence of comprehensive knowledge on HIV/AIDS among AGYW in 30 countries in SSA.

(85.0\%), were in the richest wealth quintile (81.6\%), resided in urban areas $(81.3 \%)$, were exposed to newspapers $(97.8 \%)$, radio $(88.3 \%)$ and television almost every day $(89.8 \%)$ and who used condoms (93.4\%) had higher proportions of safer sex negotiation. Finally, women who had a single current sexual partner (74.2\%) had a higher proportion of safer sex negotiation than those with multiple current sexual partners $(68.9 \%)$.

\section{Association between comprehensive knowledge on HIV/AIDS and safer sex negotiation}

Table 3 presents the binary logistic regression analysis on the association between comprehensive knowledge on HIV/AIDS and safer sex negotiation among AGYW in SSA. As shown in Model II, women who had comprehensive knowledge on HIV/AIDS were more likely to have safer sex negotiation compared with those who had no comprehensive knowledge on HIV/AIDS ( $\mathrm{AOR}=1.31,95 \% \mathrm{CI}: 1.22-1.41)$. In addition, women who had comprehensive knowledge on HIV/AIDS were more likely to have safer sex negotiation in Congo, Congo DR, Gambia, Guinea, Liberia, Ethiopia and Malawi.

\section{Discussion}

The results show that the prevalence of safer sex negotiation was high while that of comprehensive HIV/AIDS knowledge was low among AGYW in SSA in 2010 to 2019. There was also a significant 
Table 2. Bivariate analysis of safer sex negotiation, comprehensive HIV/AIDS knowledge and selected covariates of adolescent girls and young women in sub-Saharan Africa

\begin{tabular}{|c|c|c|c|c|c|c|c|c|}
\hline Variable & Weighted $n$ & Weighted \% & Can refuse sex (\%) & $p$-value & $\begin{array}{c}\text { Can ask partner to } \\
\text { use condom (\%) }\end{array}$ & $p$-value & $\begin{array}{l}\text { Safer sex } \\
\text { negotiation }\end{array}$ & $p$-value \\
\hline \multicolumn{2}{|c|}{ Comprehensive knowledge on HIV/AIDS } & & & $<0.001$ & & $<0.001$ & & $<0.001$ \\
\hline No & 21,831 & 58.4 & 60.7 & & 55.7 & & 71.3 & \\
\hline Yes & 15,533 & 41.6 & 70.5 & & 67.5 & & 80.1 & \\
\hline Age & & & & $<0.001$ & & $<0.001$ & & $<0.001$ \\
\hline $15-19$ & 9419 & 25.2 & 60.4 & & 56.0 & & 70.3 & \\
\hline $20-24$ & 27,945 & 74.8 & 66.3 & & 62.1 & & 76.5 & \\
\hline Occupational status & & & & $<0.001$ & & $<0.001$ & & $<0.001$ \\
\hline Not working & 13,830 & 37.0 & 60.8 & & 57.5 & & 71.0 & \\
\hline Working & 23,534 & 63.0 & 67.1 & & 62.4 & & 77.2 & \\
\hline Marital status & & & & $<0.001$ & & $<0.001$ & & $<0.001$ \\
\hline Married & 27,970 & 74.9 & 60.0 & & 55.1 & & 70.4 & \\
\hline Cohabiting & 9394 & 25.1 & 78.9 & & 76.9 & & 88.4 & \\
\hline Education level & & & & $<0.001$ & & $<0.001$ & & $<0.001$ \\
\hline No education & 10,295 & 27.5 & 46.4 & & 36.6 & & 56.3 & \\
\hline Primary education & 13,996 & 37.5 & 68.0 & & 66.3 & & 79.3 & \\
\hline Secondary/higher education & 13,073 & 35.0 & 74.3 & & 73.3 & & 85.0 & \\
\hline Wealth index & & & & $<0.001$ & & $<0.001$ & & $<0.001$ \\
\hline Poorest & 7414 & 19.8 & 60.6 & & 53.7 & & 70.5 & \\
\hline Poorer & 8296 & 22.2 & 63.4 & & 56.3 & & 72.1 & \\
\hline Middle & 7657 & 20.5 & 63.7 & & 59.6 & & 73.9 & \\
\hline Richer & 7652 & 20.5 & 67.4 & & 64.9 & & 77.9 & \\
\hline Richest & 6349 & 17.0 & 69.6 & & 70.2 & & 81.6 & \\
\hline
\end{tabular}


Table 2. (Continued)

\begin{tabular}{|c|c|c|c|c|c|c|c|c|}
\hline Variable & Weighted $n$ & Weighted \% & Can refuse sex $(\%)$ & $p$-value & $\begin{array}{c}\text { Can ask partner to } \\
\text { use condom }(\%)\end{array}$ & $p$-value & $\begin{array}{c}\text { Safer sex } \\
\text { negotiation }\end{array}$ & $p$-value \\
\hline Place of residence & & & & $<0.001$ & & $<0.001$ & & $<0.001$ \\
\hline Urban & 11,846 & 31.7 & 70.5 & & 68.8 & & 81.3 & \\
\hline Rural & 25,518 & 68.3 & 62.1 & & 56.8 & & 72.0 & \\
\hline Frequency of reading newspapers & & & & $<0.001$ & & $<0.001$ & & $<0.001$ \\
\hline Not at all & 31,250 & 83.6 & 62.7 & & 57.1 & & 72.6 & \\
\hline Less than once a week & 3769 & 10.1 & 75.4 & & 77.2 & & 87.0 & \\
\hline At least once a week & 2229 & 6.0 & 74.7 & & 79.2 & & 86.9 & \\
\hline Almost every day & 115 & 0.3 & 87.1 & & 89.6 & & 97.8 & \\
\hline Frequency of listening to radio & & & & $<0.001$ & & $<0.001$ & & $<0.001$ \\
\hline Not at all & 15,336 & 41.0 & 62.2 & & 56.2 & & 71.9 & \\
\hline Less than once a week & 7491 & 20.1 & 64.7 & & 60.0 & & 74.5 & \\
\hline At least once a week & 13,833 & 37.0 & 67.4 & & 64.9 & & 77.9 & \\
\hline Almost every day & 704 & 1.9 & 71.4 & & 78.1 & & 88.3 & \\
\hline Frequency of watching TV & & & & $<0.001$ & & $<0.001$ & & $<0.001$ \\
\hline Not at all & 23,130 & 61.9 & 63.8 & & 57.4 & & 73.2 & \\
\hline Less than once a week & 4692 & 12.6 & 64.4 & & 61.4 & & 74.5 & \\
\hline At least once a week & 8090 & 21.6 & 65.8 & & 65.6 & & 77.4 & \\
\hline Almost every day & 1452 & 3.89 & 76.3 & & 81.4 & & 89.8 & \\
\hline Condom used at last sex & & & & $<0.001$ & & $<0.001$ & & $<0.001$ \\
\hline No & 35,176 & 94.1 & 63.8 & & 58.7 & & 73.8 & \\
\hline Yes & 2188 & 5.9 & 80.0 & & 90.3 & & 93.4 & \\
\hline Number of sexual partners & & & & $<0.001$ & & $<0.001$ & & $<0.001$ \\
\hline One & 35,140 & 94.1 & 64.1 & & 59.7 & & 74.2 & \\
\hline Many & 2224 & 5.9 & 75.4 & & 74.0 & & 68.9 & \\
\hline
\end{tabular}


Table 3. Logistic regression on the association between comprehensive knowledge on HIV/AIDS and safer sex negotiation of adolescent girls and young women among countries in sub-Saharan Africa

\begin{tabular}{|c|c|c|}
\hline Country & $\begin{array}{c}\text { Model I } \\
\text { COR (95\% Cl; } p \text {-value) }\end{array}$ & $\begin{array}{c}\text { Model II } \\
\text { AOR (95\% Cl; } p \text {-value) }\end{array}$ \\
\hline All countries & $1.67(1.56-1.79 ;<0.001)$ & $1.31(1.22-1.41 ;<0.001)$ \\
\hline \multicolumn{3}{|l|}{ Central Africa } \\
\hline Cameroon & $1.23(0.96-1.57 ; 0.095)$ & $1.25(0.94-1.60 ; 0.136)$ \\
\hline Chad & $3.03(1.59-5.76 ; 0.001)$ & $3.16(1.51-6.62 ; 0.002)$ \\
\hline Congo & $1.05(0.58-1.91 ; 0.864)$ & $0.99(0.53-1.86 ; 0.978)$ \\
\hline Congo DR & $1.74(1.32-2.30 ;<0.001)$ & $1.59(1.20-2.11 ; 0.001)$ \\
\hline Gabon & $2.85(1.19-6.84 ; 0.019)$ & $1.93(0.71-5.19 ; 0.195)$ \\
\hline \multicolumn{3}{|l|}{ West Africa } \\
\hline Benin & $1.22(0.83-1.80 ; 0.306)$ & $1.11(0.73-1.68 ; 0.683)$ \\
\hline Burkina Faso & $1.51(1.27-1.79 ;<0.001)$ & $1.20(1.00-1.45 ; 0.053)$ \\
\hline Cote D'Ivoire & $1.26(0.81-1.96 ; 0.310)$ & $0.91(0.56-1.49 ; 0.717)$ \\
\hline Gambia & $2.06(1.56-2.72 ;<0.001)$ & $1.42(1.05-1.94 ; 0.024)$ \\
\hline Ghana & $2.60(1.16-5.83 ; 0.021)$ & $1.89(0.80-4.45 ; 0.144)$ \\
\hline Guinea & $2.14(1.54-3.00 ;<0.001)$ & $2.00(1.41-2.83 ;<0.001)$ \\
\hline Liberia & $2.06(1.19-3.56 ; 0.010)$ & $2.19(1.21-3.95 ; 0.009)$ \\
\hline Mali & $1.22(094-1.58 ; 0.133)$ & $1.13(0.86-1.48 ; 0.381)$ \\
\hline Nigeria & $1.15(0.98-1.35 ; 0.094)$ & $0.92(0.77-1.10 ; 0.356)$ \\
\hline Niger & $0.92(0.72-1.18 ; 0.502)$ & $0.85(0.65-1.12 ; 0.249)$ \\
\hline Sierra Leone & $1.15(0.86-1.54 ; 0.359)$ & $1.13(0.83-1.54 ; 0.439)$ \\
\hline Senegal & $1.36(1.11-1.67 ; 0.003)$ & $1.06(0.84-1.32 ; 0.634)$ \\
\hline Togo & $0.71(0.47-1.08 ; 0.102)$ & $0.56(0.36-0.88 ; 0.012)$ \\
\hline \multicolumn{3}{|l|}{ East Africa } \\
\hline Burundi & $1.28(0.98-1.67 ; 0.074)$ & $1.21(0.92-1.59 ; 0.178)$ \\
\hline Comoros & $1.11(0.70-1.79 ; 0.652)$ & $0.87(0.50-1.51 ; 0.619)$ \\
\hline Ethiopia & $2.37(1.81-3.10 ;<0.001)$ & $1.90(1.42-2.52 ;<0.001)$ \\
\hline Kenya & $2.39(1.78-3.22 ;<0.001)$ & $1.35(0.96-1.89 ; 0.085)$ \\
\hline Rwanda & $1.07(0.54-2.13 ; 0.839)$ & $1.16(0.57-2.36 ; 0.675)$ \\
\hline Uganda & $1.42(1.09-1.86 ; 0.011)$ & $1.15(0.87-1.52 ; 0.320)$ \\
\hline \multicolumn{3}{|c|}{ Southern Africa } \\
\hline Lesotho & $1.67(0.30-9.32 ; 0.559)$ & $0.91(0.10-8.60 ; 0.934)$ \\
\hline Malawi & $1.56(1.31-1.85 ;<0.001)$ & $1.42(1.19-1.69 ;<0.001)$ \\
\hline Mozambique & $1.51(1.03-2.22 ; 0.035)$ & $1.38(0.92-2.07 ; 0.120)$ \\
\hline Namibia & $1.40(0.20-10.07 ; 0.737$ & $1.06(0.08-14.17 ; 0.963)$ \\
\hline Zambia & $0.93(0.72-1.19 ; 0.549)$ & $0.84(0.65-1.09 ; 0.189)$ \\
\hline Zimbabwe & $1.31(0.98-1.76 ; 0.068)$ & $1.25(0.93-1.70 ; 0.137)$ \\
\hline
\end{tabular}

Model II adjusted for age, occupational status, marital status, education level, frequency of reading newspapers, frequency of listening to the radio, frequency of watching the television, condom use, number of current sexual partners, wealth index and type of place of residence. COR=Crude odds ratio; AOR: Adjusted odds ratio 
association between comprehensive HIV/AIDs knowledge and safer sex negotiation among the study respondents.

Despite the high prevalence of safer sex negotiation, the widespread reports of gender inequalities, unequal sexual power relations, rising cases of child marriages and socio-cultural practices can serve as barriers to safer sex negotiation among AGYW in SSA (UNAIDS, 2016; George et al., 2020; Melesse et al., 2020). These barriers could explain the low prevalence of comprehensive HIV/AIDS knowledge among AGYW in SSA (UNICEF, 2016; Shayo \& Kalomo, 2019; McKinnon \& Vandermorris, 2019). The high prevalence of safer sex negotiation in SSA reported in this study is, however, consistent with a previous study conducted in Ethiopia (De Coninck et al., 2014). This could be attributed to the education level of the majority of the respondents in the present study, as most (72.5\%) had completed at least primary education. Young women who are educated are more likely to be able to negotiate for safer sex compared with their counterparts who are not educated (De Coninck et al., 2014). The low prevalence of comprehensive HIV/ AIDS knowledge among AGYW in SSA found in this study is also consistent with the findings of previous studies (Idele et al., 2014; Asaolu et al., 2016). A possible reason for this finding could be the place of residence of the respondents, as the majority (68.3\%) were living in rural areas where access to comprehensive sex education is sometimes a problem (Secor-Turner et al., 2017).

The low prevalence of comprehensive HIV knowledge among AGYW in SSA implies that the global target of $90 \%$ by 2020 (UNAIDS, 2016) was not achieved as a result of the variations in the prevalence of comprehensive HIV/AIDS knowledge among the selected countries. For instance, while some countries (Rwanda, Kenya and Burundi) had a high prevalence of comprehensive HIV/AIDS knowledge, others (Congo, Benin and Ghana) had a low prevalence. This observation falls short of the intention of providing comprehensive sex education in the countries of SSA. The sub-region is still far from meeting the $95 \%$ target by 2030 given the slow progress so far.

A key finding of this study is the significant association between comprehensive HIV/AIDS knowledge and safer sex negotiation among AGYW in SSA. Specifically, those who had comprehensive knowledge of HIV/AIDS had higher odds of safer sex negotiation. Comprehensive HIV/AIDS knowledge resulted in higher safer sex negotiation in Chad and Congo DR in Central Africa; Gambia, Guinea and Liberia in West Africa; Ethiopia in East Africa; and Malawi in Southern Africa. However, it decreased safer sex negotiation among AGYW in Togo. A possible reason for this finding could be that in Togo, certain practices, such as intimate partner violence and physical violence against AGYW, prevent adolescent girls and young women from negotiating for safer sex despite their higher knowledge in comprehensive HIV/AIDS (Burgos-Soto et al., 2014). This finding corroborates findings from a previous study in Ethiopia (De Coninck et al., 2014). Comprehensive HIV/AIDS knowledge is widely reported to influence people's sexual behaviour and sexual autonomy (Iqbal et al., 2019). Also, this supports the Health Belief Model, which posits that gaining consciousness and knowledge about a health condition is the first step to informing the needed precaution (Becker, 1974). It is therefore not a surprise that AGYW in SSA who had comprehensive HIV/AIDS knowledge were more likely to negotiate for safer sex.

In sharp contrast with the findings of this study, a systematic review by Zgambo et al. (2018) showed that even though adolescents living with HIV/AIDS in SSA had comprehensive knowledge about the disease and knew their positive HIV status and its implications, they still engaged in risky sexual behaviours and could not negotiate for safer sex. Aboki et al. (2014), in their study in Nigeria, also found an insignificant relationship between comprehensive HIV knowledge and safer sex negotiation among adolescents. The disparities in the findings could be the result of differences in the socio-demographic characteristics of the respondents sampled for the various studies. Perhaps certain socio-cultural practices and the dominant patriarchal culture, which often leads to the subordination of women in sexual relationships, exacerbates women's inferiority and affords them little or no power, makes it difficult for even AGYW with comprehensive 
HIV/AIDS knowledge to negotiate for safer sex in SSA (Uchem \& Ngwa, 2014; Madiba \& Ngwenya, 2017; Sikweyiya et al., 2020).

The study had its strengths and limitations. Its key strength is its use of nationally representative DHS data from 30 sub-Saharan African countries. The DHS data collection techniques and methodology follow best practices using experienced and well-trained data collectors, resulting in a high response rate across all countries. The study findings can therefore be generalized to all adolescent girls and young women in SSA. However, it used a cross-sectional study design, and as such causality could not be deduced. Also, the relationships established between the explanatory and outcome variables may vary over time.

In conclusion, this study found that the overall prevalence of safer sex negotiation among AGYW in SSA was relatively high in 2010-2019, but that of comprehensive HIV/AIDS knowledge was relatively low. Also, a strong statistically significant association was found between comprehensive HIV/AIDS knowledge and safer sex negotiation. These findings will inform policies and programmes in the sub-Saharan African region on the crucial role of comprehensive HIV/AIDS education and knowledge in increasing safer sex practice among AGYW. The study recommends that Togo addresses certain practices, such as intimate partner violence and physical violence against AGYW adolescent girls and young women in the country, which prevent them from negotiating for safer sex, despite their high knowledge in comprehensive HIV/AIDS. Lessons could be learnt from countries like Chad, Congo DR, Gambia, Guinea, Liberia, Ethiopia, and Malawi, which have scaled-up programmes and interventions targeted at enhancing safer sex negotiation among AGYW.

Acknowledgments. The authors are grateful to the MEASURE DHS project for giving free access to the original data.

Funding. This research did not receive any specific grant from funding agencies in the public, commercial or not-for-profit sectors.

Conflicts of Interest. The authors declare that they have no conflicts of interest. There are no financial, copyright, trademark or patent implications arising from this research and no organization has any vested interest in this research.

Ethical Approval. The DHS reports that ethical clearance was obtained from the Ethics Committee of ORC Macro Inc. and ethics boards of the partner organizations of the various countries, including the Ministries of Health. The DHS follows the standards for ensuring the protection of respondents' privacy. ICF International ensures that the survey complies with the US Department of Health and Human Services' regulations for the respect of human subjects. This study was a secondary analysis of the survey data and thus no further approval was required since the data is available in the public domain. Further information about the DHS data usage and ethical standards are available at http://goo.gl/ny8T6X. The authors assert that all procedures contributing to this study comply with the ethical standards of the relevant national and institutional committees on human experimentation and with the Helsinki Declaration of 1975, as revised in 2008.

\section{References}

Aboki H, Folayan MO, Daniel U and Ogunlayi M (2014) Changes in sexual risk behaviour among adolescents: is the HIV prevention programme in Nigeria yielding results? African Journal of Reproductive Health 18, 109-117.

Agegnehu CD, Geremew BM, Sisay MM, Muchie KF, Engida ZT, Gudayu TW et al. (2020) Determinants of comprehensive knowledge of HIV/AIDS among reproductive age (15-49 years) women in Ethiopia: further analysis of 2016 Ethiopian demographic and health survey. AIDS Research and Therapy 17(1), 1-9.

Ameyaw EK, Appiah F, Agbesi CS and Kannor P (2017) Contraceptive use in Ghana: what about women empowerment? Advances in Sexual Medicine 7(1), 44-64.

Asaolu IO, Gunn JK, Center KE, Koss MP, Iwelunmor JI and Ehiri JE (2016) Predictors of HIV testing among youth in subSaharan Africa: a cross-sectional study. PLoS One 11(10), e0164052.

Atteraya MS, Kimm H and Song IH (2014) Women's autonomy in negotiating safer sex to prevent HIV: findings from the 2011 Nepal demographic and health survey. AIDS Education and Prevention 26(1), 1-12.

Badru T, Mwaisaka J, Khamofu H, Agbakwuru C, Adedokun O, Pandey SR et al. (2020) HIV comprehensive knowledge and prevalence among young adolescents in Nigeria: evidence from Akwa Ibom AIDS Indicator Survey, 2017. BMC Public Health 20(1), 1-10.

Becker MH (1974) The health belief model and personal health behaviour. Health Education Monogram 2, $324-473$. 
Bharat S, Mahapatra B, Roy S and Saggurti N (2013) Are female sex workers able to negotiate condom use with male clients? The case of mobile FSWs in four high HIV prevalence states of India. PLoS One 8(6), e68043.

Burgos-Soto J, Orne-Gliemann J, Encrenaz G, Patassi A, Woronowski A, Kariyiare B et al. (2014) Intimate partner sexual and physical violence among women in Togo, West Africa: prevalence, associated factors, and the specific role of HIV infection. Global Health Action 7(1), 23456, https://doi.org/10.3402/gha.v7.23456

Corsi DJ, Neuman M, Finlay JE and Subramanian SV (2012) Demographic and Health Surveys: a profile. International Journal of Epidemiology 41(6), 1602-1613.

Darteh EK (2020) Individual and contextual predictors of comprehensive HIV and AIDS knowledge among young females in Ghana. African Journal of AIDS Research 19(3), 222-230.

Darteh EKM, Dickson KS and Doku DT (2019) Women's reproductive health decision-making: a multi-country analysis of Demographic and Health Surveys in sub-Saharan Africa. PLoS One 14(1), e0209985.

Darteh EKM, Doku DT and Esia-Donkoh K (2014) Reproductive health decision making among Ghanaian women. Reproductive Health 11(1), 1-8.

De Coninck Z, Feyissa IA, Ekström AM and Marrone G (2014) Improved HIV awareness and perceived empowerment to negotiate safe sex among married women in Ethiopia between 2005 and 2011. PLoS One 9(12), e115453.

Exavery A, Kanté AM, Jackson E, Noronha J, Sikustahili G, Tani K et al. (2012) Role of condom negotiation on condom use among women of reproductive age in three districts in Tanzania. BMC Public Health 12(1), 1-11.

George AS, Amin A, de Abreu Lopes CM and Ravindran TS (2020) Structural determinants of gender inequality: why they matter for adolescent girls' sexual and reproductive health. BMJ 368, 16985

Hatt LE and Waters HR (2006) Determinants of child morbidity in Latin America: a pooled analysis of interactions between parental education and economic status. Social Science \& Medicine 62(2), 375-386.

Idele P, Gillespie A, Porth T, Suzuki C, Mahy M, Kasedde S and Luo C (2014) Epidemiology of HIV and AIDS among adolescents: current status, inequities, and data gaps. Journal of Acquired Immune Deficiency Syndromes 66(2), S144-S153.

Iqbal S, Maqsood S, Zafar A, Zakar R, Zakar MZ and Fischer F (2019) Determinants of overall knowledge of and attitudes towards HIV/AIDS transmission among ever-married women in Pakistan: evidence from the Demographic and Health Survey 2012-13. BMC Public Health 19(1), 1-14.

McKinnon B and Vandermorris A (2019) National age-of-consent laws and adolescent HIV testing in sub-Saharan Africa: a propensity-score matched study. Bulletin of the World Health Organization 97(1), 42-50.

Madiba S and Ngwenya S (2017) Cultural practices, gender inequality and inconsistent condom use increase vulnerability to HIV infection: narratives from married and cohabiting women in rural communities in Mpumalanga province, South Africa. Global Health Action 10 (supplement 2), 1341597.

Mandiwa C, Namondwe B and Munthali M (2021) Prevalence and correlates of comprehensive HIV/AIDS knowledge among adolescent girls and young women aged 15-24 years in Malawi: evidence from the 2015-16 Malawi demographic and health survey. BMC Public Health 21(1), 1-9.

Mavhu W, Rowley E, Thior I, Kruse-Levy N, Mugurungi O, Ncube G and Leclerc-Madlala S (2018) Sexual behavior experiences and characteristics of male-female partnerships among HIV positive adolescent girls and young women: qualitative findings from Zimbabwe. PLoS One, 13(3), e0194732.

Melesse DY, Mutua MK, Choudhury A, Wado YD, Faye CM, Neal S and Boerma T (2020) Adolescent sexual and reproductive health in sub-Saharan Africa: who is left behind? BMJ Global Health 5(1), e002231.

Mugweni E, Omar M and Pearson S (2014) Understanding barriers to safer sex practice in Zimbabwean marriages: implications for future HIV prevention interventions. Health Education Research 30(3), 388-399.

Mwale M and Muula AS (2018) Effects of adolescent exposure to behaviour change interventions on their HIV risk reduction in Northern Malawi: a situation analysis. SAHARA-J: Journal of Social Aspects of HIV/AIDS 15(1), 146-154.

Ochako R, Ulwodi D, Njagi P, Kimetu S and Onyango A (2011) Trends and determinants of comprehensive HIV and AIDS knowledge among urban young women in Kenya. AIDS Research and Therapy 8(1), 1-8.

Peng YK, Hight-Laukaran V, Peterson AE and Perez-Escamilla R (1998) Maternal nutritional status is inversely associated with lactational amenorrhea in Sub-Saharan Africa: results from demographic and health surveys II and III. Journal of Nutrition 128(10), 1672-1680.

Saul J, Bachman G, Allen S, Toiv NF, Cooney C and Beamon TA (2018) The DREAMS core package of interventions: a comprehensive approach to preventing HIV among adolescent girls and young women. PLoS One 13(12), e0208167.

Sathiyasusuman A (2015) Associated risk factors of STIs and multiple sexual relationships among youths in Malawi. PLoS One 10(8), e0134286.

Secor-Turner M, Randall BA, Christensen K, Jacobson A and Loyola Meléndez M (2017) Implementing community-based comprehensive sexuality education with high-risk youth in a conservative environment: lessons learned. Sex Education 17(5), 544-554.

Seidu AA, Darteh EKM, Kumi-Kyereme A, Dickson KS and Ahinkorah BO (2020) Paid sex among men in sub-Saharan Africa: Analysis of the demographic and health survey. SSM-Population Health 11, 100459. 
Shayo FK and Kalomo MH (2019) Prevalence and correlates of sexual intercourse among sexually active in-school adolescents: an analysis of five sub-Sahara African countries for the adolescent's sexual health policy implications. BMC Public Health 19, 1285.

Sikweyiya Y, Addo-Lartey AA, Alangea DO, Dako-Gyeke P, Chirwa ED, Coker-Appiah D et al. (2020) Patriarchy and gender-inequitable attitudes as drivers of intimate partner violence against women in the central region of Ghana. BMC Public Health 20, 1-11, https://doi.org/10.1186/s12889-020-08825-Z

Siziya S, Muula AS and Rudatsikira E (2008) HIV and AIDS-related knowledge among women in Iraq. BMC Research Notes 1(1), 1-6.

Sunmola AM, Mayungbo OA, Fayehun OA, Opayemi RS and Morakinyo LA (2018) Is women's tendency to negotiate safer sex another opportunity for intimate partner violence in Nigeria? Journal of Interpersonal Violence 36 (7-8), NP3624NP3645.

Uchem RN and Ngwa SE (2014) Subordination of women in $21^{\text {st }}$ century Africa: cultural sustainability or a new slavery? Implications for educational development. Church and Society 4(24), 143-150.

UNAIDS (2016) HIV Prevention Among Adolescent and Among Adolescent Girls \& Young Women. URL: https://www.unaids. org/sites/default/files/media_asset/UNAIDS_HIV_prevention_among_adolescent_girls_and_young_women.pdf on 08/ 02/2021 (accessed 17th June 2021).

Von Elm E, Altman DG, Egger M, Pocock SJ, Gøtzsche PC and Vandenbroucke JP (2007) The Strengthening the Reporting of Observational Studies in Epidemiology (STROBE) statement: guidelines for reporting observational studies. Annals of Internal Medicine 147(8), 573-577.

Wang W, Alva S and Wang S (2012) HIV-Related Knowledge and Behaviors Among People Living with HIV in Eight High HIV Prevalence Countries in sub-Saharan Africa. ICF International. URL: https://dhsprogram.com/publications/publicationas29-analytical-studies.cfm (accessed on 6th June, 2021).

World Health Organization (WHO) (2018) Fact Sheet on HIV and AIDS. URL: https://www.who.int/en/news-room/factsheets/detail/hiv-aids (accessed 17th June 2021).

Zgambo M, Kalembo FW and Mbakaya BC (2018) Risky behaviours and their correlates among adolescents living with HIV in sub-Saharan Africa: a systematic review. Reproductive Health 15, 180.

Cite this article: Frimpong JB, Budu E, Adu C, Mohammed A, Tetteh JK, Seidu A-A, and Ahinkorah BO (2022). Comprehensive HIV/AIDS knowledge and safer sex negotiation among adolescent girls and young women in subSaharan Africa. Journal of Biosocial Science 54, 991-1003. https://doi.org/10.1017/S0021932021000493 